\title{
Effect of using PCM as Cooling Medium in Different Types of Heat Sinks
}

\author{
Tanushree $\mathrm{P}$ \\ Dept. of Electrical and Electronics Engineering, \\ Dr. Ambedkar Institute of Technology \\ Mallathally, Bangalore,-590056
}

\begin{abstract}
Engineers, those who are tasked to design modern electronic devices face many issues related to smaller packages with more components. This leads to more power dissipation. Hence cooling of devices becomes a necessity. Heat sinks are inevitably are used for thermal management of the Electronic devices. This paper compares temperature variations from inlet to outlet for different types of heat sinks placed in air and fluid domain and ways to increase efficiency of heat sinks using phase change materials are investigated through simulations using Ansys fluent simulation tool.
\end{abstract}

Keywords: Heat sink, temperature, PCM (Phase change materials), thermal management.

\section{INTRODUCTION}

Electronic equipments were traditionally used in industrial applications. But in modern life, they have made their way in almost all accessories frequently used in day to day life to costly industrial appliances. The power consumption and hence heat dissipation is one of the areas to be investigated, as inappropriate heat dissipation may lead to many problems like higher temperature which leads to more power leakage and hence decreases device reliability. Standard cooling techniques like fan, are not effective for heat dissipation in small packages [1]. So, many types of heat sinks are used to reduce the temperature and increase efficiency of device during continuous operation over long periods. In present work, thermal management of chip is made using aluminium heat sink. Aluminium is lightest, easy to handle and to install. At the same time it has high thermal conductivity and good air pressure resisting capacity. Upon everything, it has low cost with high efficiency.

Evolution of cooling techniques started from using fan as a cooling source. With time, different cooling techniques were invented. Active cooling requires external devices for heat transfer. Components like fan are used when natural convection is not sufficient to remove heat. [2]

Passive cooling uses radiation or convection for heat transfer[3]. It does not need power for heat transfer. Ex: Heat sinks. In current market, heat sink plays an important role as a cooling substance.

\section{A. Heat sinks}

It is a thermal device and a heat exchanger, which absorbs heat from electronic devices and transfers it to other medium by conduction where the medium may be air or phase change material (PCM). In this work, results of both air and PCM as heat conducting medium are investigated.

\author{
Dr. S. Vasudevamurthy \\ Dept. of Electrical and Electronics Engineering, \\ Dr. Ambedkar Institute of Technology \\ Mallathally, Bangalore-590056
}

There are many types of heat sinks in which cylindrical pin fin, square pin fin and bonded fin type are most prominently used [4].

i.Pin fin type heat sink

Pin fin heat sink differs from other heat sinks as it has pins that are extended from its base. These pins are of various shapes like elliptical, cylindrical and square. Pin fin type heat sink is more efficient than bonded fin heat sink because it allows coolant to flow on almost all the parts of its surface

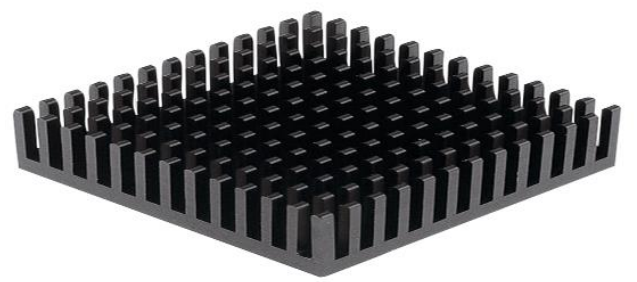

Fig.1: Pin fin type heat sink [1]

In case, if fluid medium is used as coolant, they perform in better manner when placed in tilted position as this position helps fluid to flow through heat sink easily [2]. They are perfect for spot lights, shot lights as they are adjustable. With increase in number of pins efficiency increases as it allows more coolant through it. This heat sink is cheaper. It has one disadvantage. They can be used only where surface is in direct contact with coolant nearby [5]

ii. Bonded fin type heat sinks.

This type of heat sink is made up of aluminium or copper plate first and then combined with heat sink with grooves. One advantage in this type of heat sink is different materials can be used for plate and fins. Heat dissipation ability is good. Main disadvantage is it provides less surface area for cooling and is costly [3].

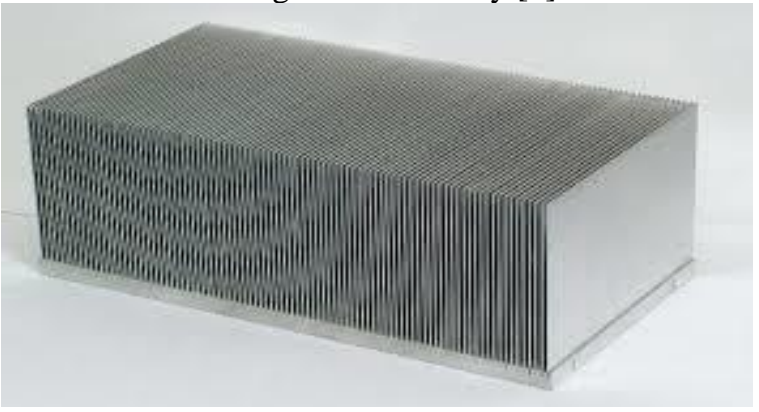

Fig.2: bonded fin type heat sink [5] 
In present work, aluminium is chosen as heat sink material and results of cylindrical pin fin type, square pin fin type and bonded pin type heat sinks are studied through simulations and compared with both air and fluid as cooling medium.

\section{B. Simulation setup}

Heat sink measuring $20 \times 20 \times 6 \mathrm{~mm}$ is taken for study. Three types of heat sinks i.e. cylindrical pin fin type, square pin fin type and bonded pin type heat sinks are compared and results are recorded.

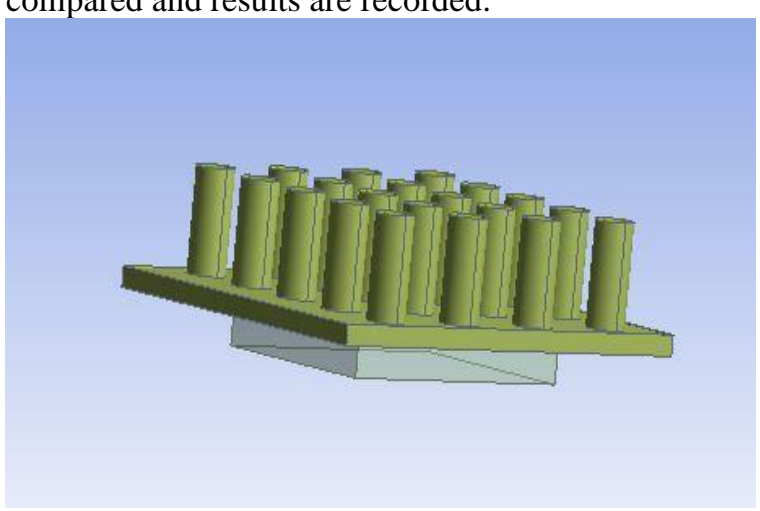

Fig 3: SolidWorks drawing of heat sink

The experimental setup shown in fig. 3 is placed on an electronic chip. The design is made using SolidWorks.

\section{Heat transfer technique.}

The heat produced by electronic chip will be absorbed by heat sink and will be transferred through conduction and then heat will be carried out by the fluid by convection and radiation [5].

Conduction, Convection and Radiation are three processes that take place in heat transfer process.

1. Conduction: Transfer of energy in the form of heat from higher energy to lower energy substance [5] $q "=-K . \nabla T$

Where;

$q^{\prime \prime}$ is the heat transfer rate $\left(W / m^{2}\right)$

$\mathrm{K}$ is the thermal conductivity $\left(W / m .{ }^{0} K\right)$

$\nabla T=\left(i \frac{\partial T}{\partial X}+j \frac{\partial \mathrm{T}}{\partial Y}+k \frac{\partial T}{\partial Z}\right)$

2. Convection: It is heat transfer between fluid in motion and a solid surface [5].

$q^{\prime \prime}=-h\left(T_{1}-T_{2}\right)$

Where;

$\mathrm{h}$ is the convective heat transfer coefficient ( $W$

$\left./ m^{2}{ }^{\circ} K\right)$

$T_{l}$ is the surface temperature $\left({ }^{\circ} \mathrm{K}\right)$

$T_{2}$ is the fluid temperature $\left({ }^{\circ} \mathrm{K}\right)$

3. Radiation: It is energy emitted by substance or matter which is in non-zero temperature [5].

$q "=J-G$

Where;

$\mathbf{J}$ is the radiosity $\left(W / m^{2}\right)$

$\mathrm{G}$ is the irradiation $\left(W / \mathrm{m}^{2}\right)$

$J=E+\rho G$

$\mathrm{E}$ is the emissive power $\left(\mathrm{W} / \mathrm{m}^{2}\right)$

$$
\begin{gathered}
\rho \text { is the reflectivity } \\
\text { Energy balance: } \\
\frac{\partial}{\partial t}(\rho C p+T)=\frac{\partial}{\partial x}\left(k \frac{\partial T}{\partial x}\right)+\frac{\partial}{\partial y}\left(k \frac{\partial T}{\partial y}\right)+\frac{\partial}{\partial z}\left(k \frac{\partial T}{\partial z}\right)
\end{gathered}
$$

\section{ANSYS FLUENT MODELING}

This study is done using Ansys fluent simulation tool. For the sake of design, testing and operation, many multiphysics engineering related softwares are developed and marketed by Ansys. Ansys fluent is a type of software where larger structures are sectioned into small components where each are modeled and tested individually. A user may start by defining the dimensions of an object, and then adding weight, temperature and other physical properties. Finally, the Ansys software simulates and analyzes movement, fatigue, fractures, fluid flow, temperature distribution, electromagnetic efficiency and other effects over time [6].

\section{SIMULATION PROCESS}

In present work, the solution is updated every 0.01 second with 50 iterations per time step. In this study, heat sink is placed in air as domain which has one inlet and one outlet and is studied at room temperature of $15^{\circ} \mathrm{C}$ to make our study more effective. Any temperature can be taken as room temperature. This temperature may further change at the inlet due to the influence of heat of heat sink.

The heat sink shown in fig. 4 is cylindrical pin heat sink placed in above mentioned conditions.

Simulation process has 5 steps:

1. Geometry: In present work, SolidWorks simulation tool is used to create the geometry shown in fig. 4. So, the geometry file is imported from SolidWorks.

2. Meshing: The modeled geometry will be meshed. There are many shapes in meshing like hexahedron meshing, triangle etc. The mesh influences the accuracy, convergence and speed of simulation. Hence meshing is important factor in Ansys simulation.

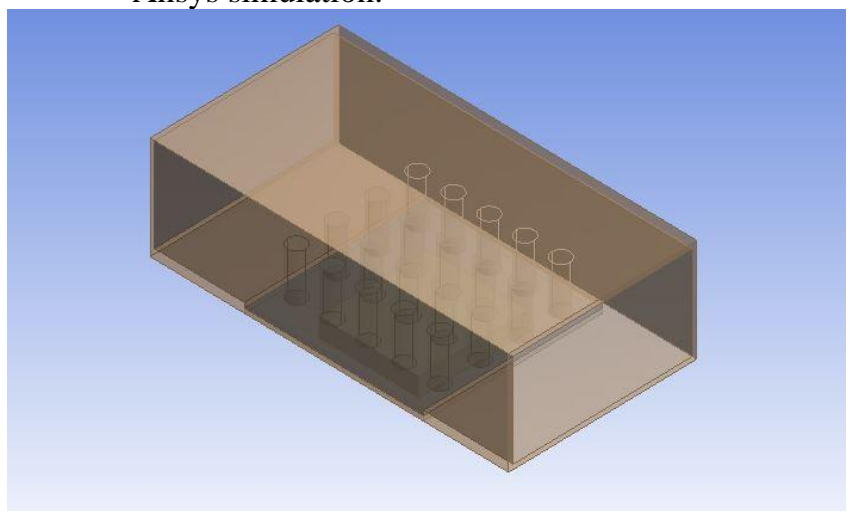

Fig 4: Heat sink placed in air as cooling domain 


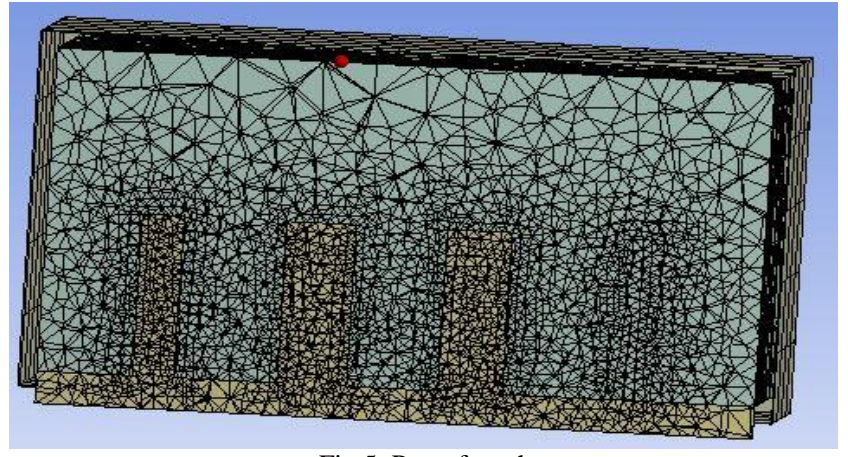

Fig 5: Part of mesh

3. Setup: Required input information like temperature, pressure, type of initialization, mesh interfacing etc. are given here.

4. Solution: The Ansys simulation tool calculates solution by using finite element analysis (FEA).

5. Results: The results will be pictorial representation, which helps the user to understand it easily. The below shown pictures (fig. 6 to fig. 10, fig. 13 and fig. 14) are results for present work.

In present work, the following conditions are chosen for all three types of heat sinks.

Time: Transient analysis is chosen, as it helps to get detailed output and also helps to show gradual variation of temperature from inlet to outlet and temperature difference between top and bottom of heat sink.

Energy: It is turned $\mathbf{O N}$ as heat is also a form of energy and we need to get temperature output.

Material: Air as domain and aluminium as heat sink material.

Cell zones: Here we have 3 cell zones namely; chip (which is considered as heating source), heat sink and domain where heat sink is placed.

The following states must be chosen

\section{Chip: Solid}

\section{Heat sink: Solid}

Domain: Fluid (In Ansys, even air is considered as fluid)

For chip, a heat flux source is provided so that it can heat and allows heat sink to absorb heat. Hence one energy source is provided for chip.

Boundary conditions: Here inlet is selected as velocity inlet as air enters inlet with a certain velocity. The magnitude of velocity is taken as $\mathbf{1 m} / \mathbf{s}$. The outlet is selected to be pressure outlet. The atmospheric temperature is selected as $\mathbf{1 5}{ }^{\mathbf{0}} \mathbf{C}$. Any temperature can be selected as atmospheric temperature.

Mesh interface: In this work, we have 2 types of material. Air, which Ansys considers as fluid and another one is solid. Ansys is very much efficient to make difference between these two materials during meshing. Hence we have to couple those two so that Ansys can make difference while meshing. This work is done during mesh interface. Here coupled wall is turned $\mathbf{O N}$ so that Ansys can find out temperature of both solid and liquid without any problem.

Solution initialization: Hybrid initialization is selected for more accuracy. It uses boundary conditions before giving output.

Run calculation:

\section{Time step size $=0.01$ \\ Number of time steps $=200$ \\ Maximum iterations $=\mathbf{4 0}$}

So, Ansys is instructed to do at least 40 iterations if convergence is not reached.

Calculation activity: Here the file where data is be saved is chosen along with all the quantities which is to be calculated. In this work, temperature, pressure and velocity is chosen.

\section{Frequency (time step): 3}

This is because, the output will be calculated for thousands of times and there is no need to save all data. This is the instruction for Ansys to save one output after every three outputs.

After giving all the instructions to Ansys, the results provided by Ansys are as discussed below.

\section{Results}

Temperature distribution in different types of heat sink placed in air medium is as shown from fig. 6 to fig. 10 . Left hand side in cylindrical fin pin type of heat sink (fig. 6) has inlet and right hand side has outlet for cylindrical fin pin heat sink. As mentioned earlier, the atmospheric temperature is $15{ }^{\circ} \mathrm{C}$. The blue part represents cold air at temperature $17.839{ }^{\circ} \mathrm{C}$ is entering heat sink. The increase in temperature by $2.839{ }^{\circ} \mathrm{C}$ is due to the influence of temperature of heat sink which is placed inside air domain. The temperature of air increases due to convection and hence the heat is transferred from heat sink to air which is cooling medium. The right hand side has red color and indicates the air coming out is hot i.e. $\quad 21.65{ }^{\circ} \mathrm{C}$ and hence heat is removed from both chip and heat sink. The temperature at inlet is $17.839{ }^{\circ} \mathrm{C}$ and outlet is $21.65{ }^{\circ} \mathrm{C}$. Hence the heat is removed effectively.

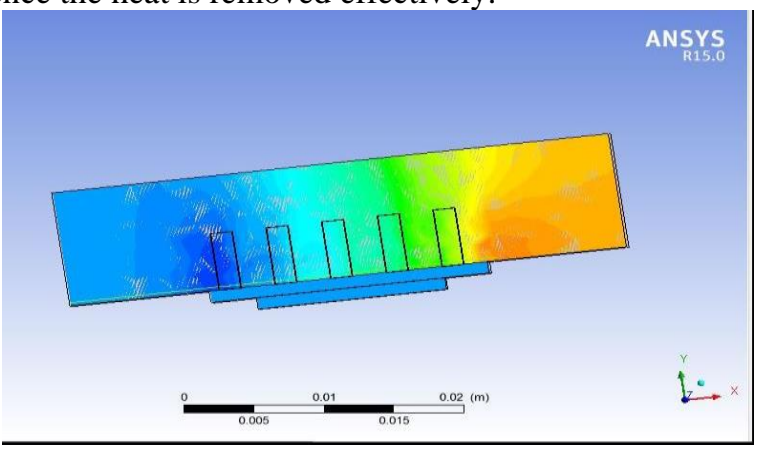

Fig 6: Temperature distribution in cylindrical pin type of heat sink.

Similarly the fig. 7 shows temperature simulation results for square pin fin heat sink placed in air as cooling medium at same room temperature i.e. $15^{\circ} \mathrm{C}$.

The temperature at inlet is $17.839{ }^{\circ} \mathrm{C}$ and outlet is $\mathbf{2 0 . 3}$ ${ }^{0} \mathrm{C}$. Compared to readings of cylindrical pin fin type of heat 
sink, heat removal is $1.35{ }^{\circ} \mathrm{C}$ less here. Hence the heat removal is less effective than cylindrical pin type heat sink.

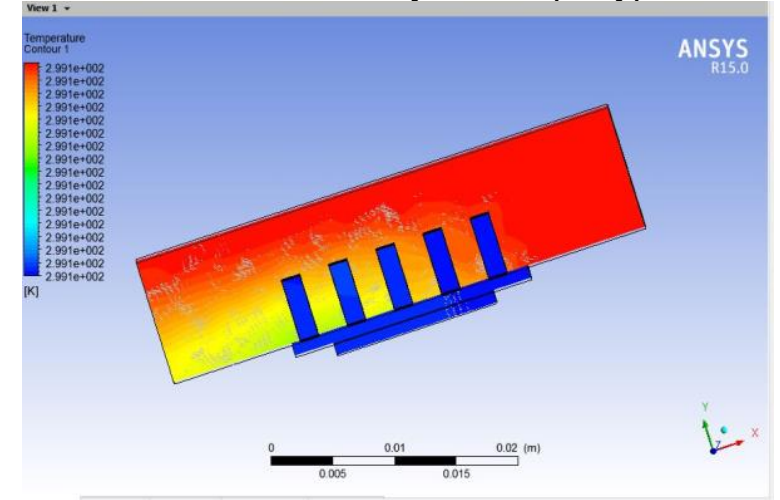

Fig 7: Temperature distribution in square pin type of heat sink.

The fig. 8 shows temperature distribution in bonded fin heat sink with air as cooling medium at room temperature of $15{ }^{\circ} \mathrm{C}$.

The temperature at inlet is $\mathbf{1 7 . 8 3 9}{ }^{\circ} \mathrm{C}$ and outlet is $\quad \mathbf{1 9 . 0 3}$ ${ }^{0} \mathbf{C}$. This type of heat sink has less space in between fins for air to pass through it. So air cannot cover complete base of heat sink compared to pin fin type. Hence blue color at right hand side shows the air coming out of heat sink is not so hot i.e. $19.03{ }^{\circ} \mathrm{C}$ compared to inlet temperature i.e. $17.839{ }^{\circ} \mathrm{C}$. It can be observed that the rate of heat transfer from bonded type of heat sink is less when compared to cylindrical pin fin type of heat sink by $2.62{ }^{\circ} \mathrm{C}$ and hence this type of heat sink is not so efficient in heat removal from heating source compared to cylindrical pin fin type of heat sink.

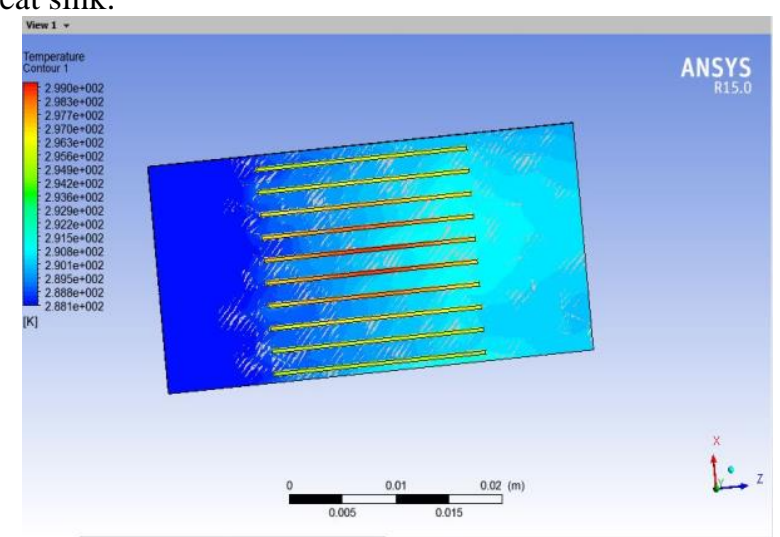

Fig 8: Temperature distribution in bonded fin type of heat sink.

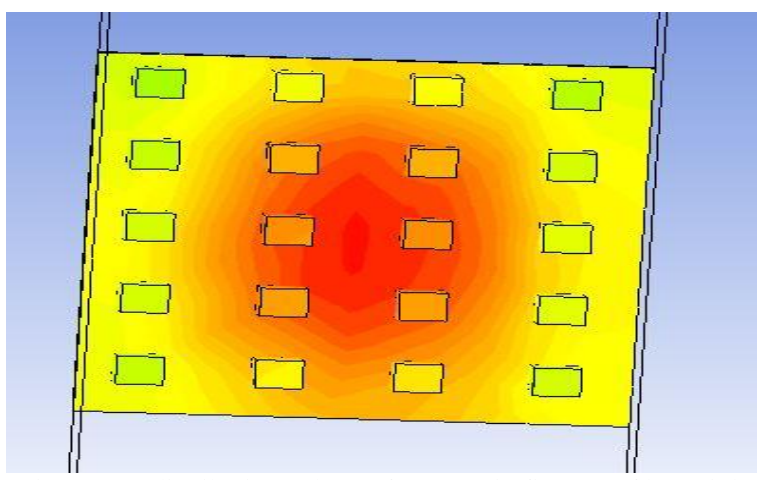

Fig 9: Heat distribution at base of square pin fin type of heat sink

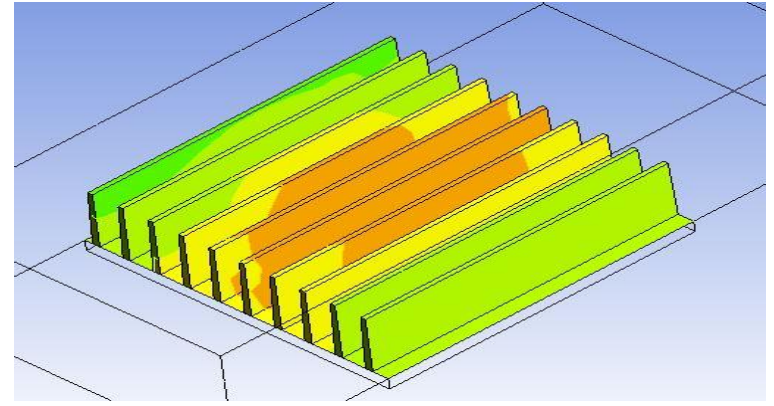

Fig 10: Heat distribution at fins of bonded fin type of heat sink

Table 1: Heat flow co-efficient values for different flow type [7].

\begin{tabular}{|c|c|}
\hline Flow type & $\left(\mathrm{W} / \mathrm{m}^{2} \mathrm{~K}\right)$ \\
\hline $\begin{array}{l}\text { Forced convection; low speed flow of air } \\
\text { over a surface }\end{array}$ & 10 \\
\hline $\begin{array}{l}\text { Forced convection; moderate speed } \\
\text { flow of air over a surface }\end{array}$ & 100 \\
\hline $\begin{array}{l}\text { Forced convection; moderate speed } \\
\text { cross- flow of air over a cylinder }\end{array}$ & 200 \\
\hline $\begin{array}{l}\text { Forced convection; moderate flow of } \\
\text { water in a pipe }\end{array}$ & 3000 \\
\hline Forced Convection; molten metals & $\begin{array}{l}2000 \text { to } \\
45000\end{array}$ \\
\hline $\begin{array}{l}\text { Forced convection; boiling water in a } \\
\text { pipe }\end{array}$ & 50,000 \\
\hline Forced Convection - water and liquids & $\begin{array}{c}50 \text { to } \\
10000\end{array}$ \\
\hline Free Convection - gases and dry vapors & 5 to 37 \\
\hline Free Convection - water and liquids & $\begin{array}{l}50 \text { to } \\
3000\end{array}$ \\
\hline Air & 10 to 100 \\
\hline $\begin{array}{l}\text { Free convection; vertical plate in air with } \\
30^{\circ} \mathrm{C} \text { temperature difference }\end{array}$ & 5 \\
\hline Boiling Water & $\begin{array}{l}3.000 \text { to } \\
100.000\end{array}$ \\
\hline
\end{tabular}

To calculate convection heat flow, let heat transfer coefficient (h) for forced convection of air be $100 \mathrm{~W} / \mathrm{m}^{2} . \mathrm{K}$ referring to table in Table 1 . The heat flow for different types of heat sinks are as in Table 2.

Table 2: Heat flow calculated with air as cooling medium

\begin{tabular}{|l|l|l|l|}
\hline & $\begin{array}{l}\text { Cylindrical } \\
\text { fin type }\end{array}$ & $\begin{array}{l}\text { Square } \\
\text { pin fin } \\
\text { type }\end{array}$ & $\begin{array}{l}\text { Bonded } \\
\text { pin fin } \\
\text { type }\end{array}$ \\
\hline $\begin{array}{l}\text { Inlet } \\
\text { temperature(K) }\end{array}$ & 290.979 & 290.979 & 290.979 \\
\hline $\begin{array}{l}\text { Outlet } \\
\text { temperature(K) }\end{array}$ & 294.79 & 293.44 & 292.18 \\
\hline $\begin{array}{l}\text { Temperature } \\
\text { difference between } \\
\text { inlet and outlet }\end{array}$ & $1.309 \%$ & $0.845 \%$ & $0.412 \%$ \\
\hline $\begin{array}{l}\text { Convectional heat } \\
\text { flow(W/m²) } \\
q^{\prime \prime}=h(T 2-T 1)\end{array}$ & 381.1 & 246.1 & 120.1 \\
\hline
\end{tabular}

The heat sink placed in air domain removes heat from heating source. From above table, it is evident that the temperature difference between inlet and outlet is decreasing from cylindrical type of heat sink to bonded fin type of heat sink. The cylindrical pin fin type of heat sink reduced the temperature of chip by $3.811{ }^{\circ} \mathrm{C}$.Similarly, square pin fin and bonded fin type of heat sink reduced the temperature of chip by $2.461{ }^{\circ} \mathrm{C}$ and $1.201{ }^{0} \mathrm{C}$ 
respectively. Hence cylindrical pin fin heat sink acts more effectively in heat removal than square pin fin and bonded fin type of heat sink. Now heat sink's efficiency is studied by placing PCM (phase change material).

\section{PHASE CHANGE MATERIALS (PCM)}

A PCM is a material which absorbs or releases energy at phase transition to give useful cooling. PCM based heat sinks effectively store heat dissipated from electronic components and then release energy stored during OFF period i.e. when the electronic equipment where the PCM is placed is turned OFF. [8].

\section{WORKING:}

The fig. 12 explains how PCM works [8].

In this case, initially PCM will be in solid state. With rise in temperature, the PCM starts melting. Once PCM starts melting, the temperature stops increasing as the heat released by chip will be used in melting. Once PCM melts completely, it reaches liquid state the temperature further starts increasing. So PCM based heat sinks store heat dissipated from heating component. Further when electronic component is in OFF state, PCM solidifies.

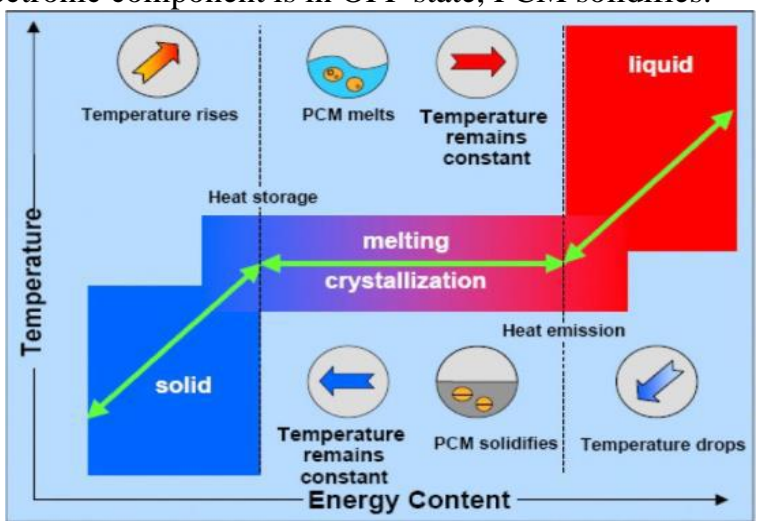

Fig 12: Working of PCM [8]

Using PCM has many benefits like heat storage, no moving parts, compatible to any type of heat sink and is reliable. In present work, all the input parameters including aluminium heat sink are same as that of air domain, but the air as domain is replaced with methyl-silylidine (sich3) which is chosen as phase change material.

Methyl-silylidine (sich3), is an organic compound with very effective heat absorbing capacity as it can freeze without cooling during crystallization.

The figures 13 and 14 show the results for using PCM along with heat sinks.

The inlet temperature for bonded fin type heat sink is $17.839{ }^{\circ} \mathrm{C}$ and outlet temperature is $20.91^{\circ} \mathrm{C}$.

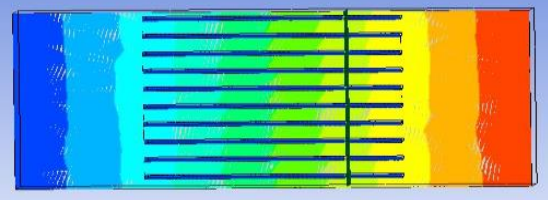

Fig 13: Temperature distribution using PCM for bonded fin type heat sink
The inlet temperature for cylindrical pin fin type heat sink is $17.839{ }^{\circ} \mathrm{C}$ and outlet temperature is $23.49{ }^{\circ} \mathrm{C}$. The inlet temperature for square pin fin type heat sink is $17.839{ }^{\circ} \mathrm{C}$ and outlet temperature is $22.04{ }^{\circ} \mathrm{C}$.

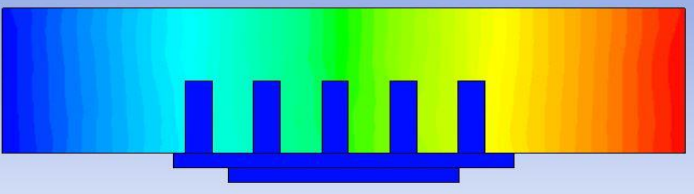

Fig 14: Temperature distribution using PCM for square pin type heat sink

To calculate convection heat flow, let heat transfer coefficient (h) for convection with PCM as fluid is $200 \mathrm{~W} / \mathrm{m}^{2}$.K referring to table 1 . The heat flow for different types of heat sinks are as Table 3 .

Table 3: Convectional heat flow calculated with PCM as fluid medium

\begin{tabular}{|c|c|c|c|}
\hline & $\begin{array}{l}\text { Cylindrical } \\
\text { fin type }\end{array}$ & $\begin{array}{l}\text { Square fin } \\
\text { type }\end{array}$ & $\begin{array}{l}\text { Bonded } \\
\text { fin type }\end{array}$ \\
\hline $\begin{array}{l}\text { Inlet } \\
\text { temperature }(\mathrm{K})\end{array}$ & 290.979 & 290.979 & 290.979 \\
\hline $\begin{array}{l}\text { Outlet } \\
\text { temperature }(\mathrm{K})\end{array}$ & 296.64 & 295.18 & 294.05 \\
\hline $\begin{array}{l}\text { Temperature } \\
\text { difference between } \\
\text { inlet and outlet }\end{array}$ & $1.945 \%$ & $1.443 \%$ & $1.055 \%$ \\
\hline $\begin{array}{l}\text { Convectional heat } \\
\text { flow }\left(\mathrm{W} / \mathrm{m}^{2}\right) \\
q^{\prime \prime}=h(T 2-T 1)\end{array}$ & 1132.2 & 840.2 & 614.2 \\
\hline
\end{tabular}

From above table, it is noticed that the temperature difference between inlet and outlet is decreasing from cylindrical type of heat sink to bonded fin type of heat sink and the temperature difference between inlet and outlet is more when compared to table 2, which is the result of heat sink placed in air domain. The cylindrical pin fin type of heat sink reduced the temperature of chip by 5.661 ${ }^{0} \mathrm{C}$.Similarly, square pin fin and bonded fin type of heat sink reduced the temperature of chip by $\quad 4.201{ }^{\circ} \mathrm{C}$ and $3.071{ }^{\circ} \mathrm{C}$ respectively. Hence again, cylindrical pin fin heat sink acts more effectively in heat removal than square pin fin and bonded fin type of heat sink.

By comparing the Table 2 and Table 3 i.e. results for air and PCM as cooling medium, we can notice that the temperature difference between inlet and outlet is more by $7.83 \%$ for cylindrical pin fin type of heat sink, $7.89 \%$ for square pin fin type of heat sink, $8.99 \%$ for bonded fin type of heat sink by using PCM as cooling medium than that of air as cooling medium. Hence using PCM along with heat sink increases heat removal efficiency of heat sink.

Table 4: Comparison table for outlet temperature with air and with PCM domain

\begin{tabular}{|l|l|l|l|}
\hline & $\begin{array}{l}\text { Cylindrical } \\
\text { pin fin type }\end{array}$ & $\begin{array}{l}\text { Square pin } \\
\text { fin type }\end{array}$ & $\begin{array}{l}\text { Bonded pin } \\
\text { fin type }\end{array}$ \\
\hline $\begin{array}{l}\text { Temperature } \\
\text { difference } \\
\text { between inlet } \\
\text { and outlet for }\end{array}$ & $1.309 \%$ & $0.845 \%$ & $0.412 \%$ \\
\hline
\end{tabular}




\begin{tabular}{|l|l|l|l|}
\hline air domain & & & \\
\hline Temperature & $1.945 \%$ & $1.443 \%$ & $1.055 \%$ \\
difference \\
between inlet & & & \\
and outlet for & & & \\
PCM domain & & & \\
\hline
\end{tabular}

From table 4 , it is noticed that outlet temperature for all three types of heat sink is more by using PCM as domain for cooling purpose. Hence it is proved that by integrating PCM, more heat can be absorbed from heating component, compared to that of using only heat sink in electronic devices. Heat dissipated can be removed effectively using PCM.

Main motive of the paper is to provide some brief knowledge about the efficiency improvements that can be made in pin fins to increase heat transfer rate.

Main motive of the paper is to provide some brief knowledge about the efficiency improvements that can be made in pin fins to increase heat transfer rate.

Main motive of the paper is to provide some brief knowledge about the efficiency improvements that can be made in pin fins to increase heat transfer rate.

Main motive of the paper is to provide some brief knowledge about the efficiency improvements that can be made in pin fins to increase heat transfer rate.

Main motive of the paper is to provide some brief knowledge about the efficiency improvements that can be made in pin fins to increase heat transfer rat

\section{CONCLUSION}

The main motive of this work is to provide a comparison of performance of heat sink placed in air and fluid domain (PCM) and improving efficiency of heat transfer rate in pin fin and bonded type of heat sink by using PCM as fluid medium.

After investigating temperature distribution in different types of heat sinks for 2 types of cooling medium i.e. air and PCM (Table 2 and table 3), it can be said that

1. Integrating PCM (phase change materials) with heat sink can improve cooling performance (Table 4) and hence efficiency of heat sink can be increased.

2. Comparing performance of 3 types of heat sinks i.e. cylindrical pin fin, square pin fin and bonded fin heat sink both in air and PCM domain (Table 2 and 3), cylindrical pin fin type is more efficient than square pin fin and bonded fin heat sink.

\section{REFERENCES}

[1] Nisar Sheik, Bhusan Kumar, Nitish Kumar Sanai, "A review paper on pin efficiency enhancement", International journal of applied engineering research. Nov 2019.

[2] Sergent, J.; Krum, A. "Thermal management handbook for electronic assemblies ", First edition, 1998.

[3] Singh Pradeep, Lal Harvinder and Ubhi Balijit Singh,"Design and analysis for heat transfer through fin with extensions", International journal of Innovative research science, engineering and technology,May 2014

[4] ABL Heatsinks, "Heatsink Design and Selection: Material".

[5] Ibrahim Mjallal, Hussien Farhat, Mohammad Hammoud ,Ali H. Assi, "Cooling Performance of Heat Sinks Used in Electronic Devices", Conference paper, Feb 2017.

[6] Lee, H.-H., "Finite Element Simulations with ANSYS Workbench 17', SDC Publications, pp. 50,2017.

[7] Sukhatme S.P, "A Textbook on Heat Transfer (Fourth ed.)" Universities Press, pp. 257-258, 2005.

[8] Kandasamy, Ravi, "Transient cooling of electronics using phase change material (PCM)-based heat sinks.", 2007.

[9] Hill, M. (n.d), "Cooling of electronic equipments",Chapter 15.

[10] Rashid, M. H., "Power electronics: circuits, devices, and applications”. Pearson Education India, 2009. 